\title{
Silicomanganese and Ferromanganese Slags Treated with Concentrated Solar Energy ${ }^{\dagger}$
}

\author{
Daniel Fernández-González *, Juan Piñuela-Noval and Luis Felipe Verdeja \\ Department of Materials Science and Metallurgical Engineering, School of Mines, Energy and Materials, \\ University of Oviedo, Oviedo, 33004 Asturias, Spain; 120195juan@gmail.com (J.P.-N.); lfv@uniovi.es (L.F.V.) \\ * Correspondence: fernandezgdaniel@uniovi.es; Tel.: +34-985104303 \\ + Presented at the 2nd International Research Conference on Sustainable Energy, Engineering, Materials and \\ Environment (IRCSEEME), Mieres, Spain, 25-27 July 2018.
}

Published:15 November 2018

\begin{abstract}
Solar energy when properly concentrated offers a great potential in high temperature applications as those required in metallurgical processes. Even when concentrated solar energy cannot compete with conventional metallurgical processes, it could find application in the treatment of wastes from these processes. These by-products are characterized by their high metallic contents, which make them interesting as they could be a raw material available in the own factory. Slags are one of these by-products. Slags are most of them disposed in controlled landfill with environmental impact, but also with economic impact associated to the storing costs and the metallic losses. Here we propose the treatment of ferromanganese and silicomanganese slags with concentrated solar energy with the purpose of evaluating the recovery of manganese from these slags.
\end{abstract}

Keywords: concentrated solar energy; manganese; environment; ferroalloys; slags

\section{Introduction}

Solar energy has taken growing interest in the last decades with the development of renewable energy sources, and particularly when properly concentrated, this energy source can be used in high temperature applications, as those that can be read in Fernández-González et al., 2018 [1], and, for instance, in our case, we used solar energy in the synthesis of calcium aluminate cement [2] and in the iron metallurgy [3].

Slags are usually recycled in the own process or disposed in controlled landfill [4-8], but they contain significant quantities of metal and recovering it from the slag could be interesting since the economic and environmental point of view. This paper is dedicated to the utilization of concentrated solar energy in synthesizing ferromanganese, and in the treatment of ferromanganese and silicomanganese slags.

\section{Materials and Methods}

Experiments were carried out in a $1.5 \mathrm{~kW}$ vertical axis solar furnace located in Odeillo and belonging to the PROMES-CNRS (Procédés, Matériaux et Énergie Solaire-Centre National de la Recherche Scientifique). The solar furnace is based on that the sun radiation strikes a heliostat, which tracks the sun and reflects the radiation towards a $2 \mathrm{~m}$. in diameter parabolic concentrator (Figure 1). This parabolic concentrator makes solar radiation converge at a focal point of $12-15 \mathrm{~mm}$. in diameter. In this way, solar radiation $\left(700-1100 \mathrm{~W} / \mathrm{m}^{2}\right)$ is concentrated by four orders of magnitude. A shutter was used to control the power applied to the sample. 


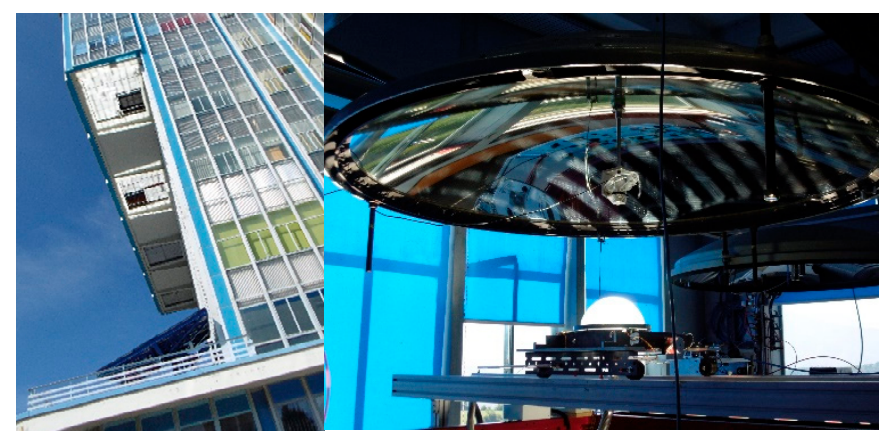

Figure 1. Experimental equipment used in the experiments. Parabolic concentrator and experimental device (right) and heliostat (left).

Mixtures of $\mathrm{Fe}_{2} \mathrm{O}_{3}, \mathrm{MnO}_{2}$ and carbon (laboratory quality reagents; different carbon excesses, 10, 15,25 and $40 \%$ wt.), were loaded in mullite crucibles of $75 \mathrm{~mm}$ in length, $12 \mathrm{~mm}$ in width and $8 \mathrm{~mm}$ in depth (see in [9] a full description of the same process used in the case of $\mathrm{Fe}_{2} \mathrm{O}_{3}+\mathrm{C}$ mixtures), having as objective synthesizing ferromanganese. A series of thermocouples were located at the bottom of the crucible (outside) to register the temperature (max. temperature $>1200{ }^{\circ} \mathrm{C}$ ). Crucible displaced at a controlled speed below the focal point to treat all the material loaded in the crucible.

Mixtures of ferromanganese and silicomanganese slags (industrial slags, Table 1), some with calcium carbonate to liberate manganese from them, were prepared separately in crucibles of tabular alumina with $55 \mathrm{~mm}$ in height, $30 \mathrm{~mm}$ in upper diameter, $25 \mathrm{~mm}$ in lower diameter and $3 \mathrm{~mm}$ in thickness of the crucible walls. The crucible was located below the focal point ( $15 \mathrm{~mm}$ in diameter) and covered with a glass hood to avoid the projections in the parabolic concentrator. Samples comprised four different types of mixtures of slags: ferromanganese (Table 1), silicomanganese (Table 1), ferromanganese with limestone and silicomanganese with limestone. The additions of limestone were performed in an attempt of forming silicates of calcium instead of silicates of manganese and thus liberating manganese from the slag. Initial slags were analyzed through x-ray diffraction, and in the case of FeMn slag it reported glaucochroite $\left((\mathrm{Ca}, \mathrm{Mn})_{2} \mathrm{SiO}_{4}\right)$, gehleneite $\left(\mathrm{Ca}_{2} \mathrm{Al}_{2} \mathrm{SiO}_{7}\right)$ and manganosite $(\mathrm{MnO})$, while in the case of $\mathrm{SiMn}$ slag it showed gehleneite $\left(\mathrm{Ca}_{2} \mathrm{Al}_{2} \mathrm{SiO}_{7}\right)$, kirschsteinite $(\mathrm{CaFeSiO})$, melilite $\left(\mathrm{Ca}_{8} \mathrm{Al}_{6} \mathrm{MgSi}_{5} \mathrm{O}_{28}\right)$ and manganese oxide (IV), in order of abundance.

Table 1. Chemical composition of the slags (above silicomanganese, and below ferromanganese).

\begin{tabular}{ccccccccccccc}
\hline Element & $\mathbf{O}$ & $\mathbf{M n}$ & $\mathbf{C a}$ & $\mathbf{S i}$ & $\mathbf{A l}$ & $\mathbf{M g}$ & $\mathbf{S}$ & $\mathbf{B a}$ & $\mathbf{K}$ & $\mathbf{N a}$ & $\mathbf{S r}$ & Others \\
Conc. (\%) & 37.12 & 19.02 & 17.76 & 12.56 & 6.569 & 2.741 & 1.189 & 1.084 & 0.6663 & 0.5670 & 0.2544 & Balance \\
\hline Element & $\mathbf{O}$ & $\mathbf{M n}$ & $\mathbf{C a}$ & $\mathbf{S i}$ & $\mathbf{A l}$ & $\mathbf{F e}$ & $\mathbf{N a}$ & $\mathbf{K}$ & $\mathbf{B a}$ & $\mathbf{T i}$ & $\mathbf{S}$ & Others \\
Conc. (\%) & 33.25 & 29.39 & 19.62 & 11.04 & 3.228 & 1.375 & 0.4204 & 0.4063 & 0.3997 & 0.2761 & 0.2031 & Balance \\
\hline
\end{tabular}

\section{Results}

Samples were analyzed using x-ray diffraction technique in powdered materials.

\subsection{Synthesis of Ferromanganese}

Partially reduced iron and manganese oxides were detected. Manganese oxide (II)(MnO) and manganese oxide (II, III) $\left(\mathrm{Mn}^{2+} \mathrm{Mn}^{3+}{ }_{2} \mathrm{O}_{4}\right)$ are the partially reduced manganese oxides as the initial manganese oxide was pyrolusite $\left(\mathrm{MnO}_{2}\right)$. Partially reduced iron phases are not typical, but when they appear they do as magnetite $\left(\mathrm{Fe}_{3} \mathrm{O}_{4}\right)$ and maghemite $\left(\gamma-\mathrm{Fe}_{2} \mathrm{O}_{3}\right.$, which is like a magnetite with vacancies) while the initial iron oxide was in the form of hematite $\left(\mathrm{Fe}_{2} \mathrm{O}_{3}\right)$. Typical phases, major components in the quantitative analysis discounting amorphous phases, were iwakiite and jacobsite $\left(\left(\mathrm{Mn}^{2+}, \mathrm{Fe}^{2+}\right)\left(\mathrm{Fe}^{3+}, \mathrm{Mn}^{3+}\right)_{2} \mathrm{O}_{4}\right)$, and the manganese oxides.

\subsection{Treatment of Ferromanganese Slag}

Calcium carbonate additions were not sufficient to produce any effect in the slag and thus phases identified in one and another type of sample were similar. In this case, as we will see in the case of 
the silicomanganese slags, silicates are the main phase in the slag. Gehlenite $\left(\mathrm{Al}_{2} \mathrm{Ca}_{2} \mathrm{O}_{7} \mathrm{Si}\right)$, glaucochroite $\left(\mathrm{CaMn}^{2+} \mathrm{SiO}_{4}\right)$ and kirschsteinite $\left(\mathrm{CaFeSiO}_{4}\right)$ were identified, the same as manganese oxides $\left(\mathrm{MnO}, \mathrm{MnO}_{2}, \mathrm{Mn}_{2} \mathrm{O}_{3}\right.$ and $\left.\mathrm{Mn}^{2+} \mathrm{Mn}^{3+}{ }_{2} \mathrm{O}_{4}\right)$. Other phases identified in these samples were: brownmillerite $\left(\mathrm{Ca} 4(\mathrm{Al}, \mathrm{Fe})_{2} \mathrm{O}_{10}\right)$, fayalite $\left(\left(\mathrm{Fe}^{2+}\right)_{2} \mathrm{SiO}_{4}\right)$, melilite $\left(\mathrm{Ca} 8 \mathrm{Al}_{6} \mathrm{MgSi}_{5} \mathrm{O}_{28}\right)$ and yoshiokaite $\left(\mathrm{Ca}(\mathrm{Al}, \mathrm{Si})_{2} \mathrm{O}_{4}\right)$.

\subsection{Treatment of Silicomanganese Slag}

The same as in the other case, calcium carbonate additions were not sufficient to produce any effect in the slag and thus phases identified in one and another type of sample were similar. Gehlenite $\left(\mathrm{Al}_{2} \mathrm{Ca}_{2} \mathrm{O}_{7} \mathrm{Si}\right)$ and kirschsteinite $\left(\mathrm{CaFeSiO}_{4}\right)$ are the main phases. Manganese oxides $\left(\mathrm{MnO}, \mathrm{Mn}_{2} \mathrm{O}_{3}\right.$ and $\left.\mathrm{Mn}^{2+} \mathrm{Mn}^{3+}{ }_{2} \mathrm{O}_{4}\right)$ are also representative in the x-ray diffraction analyses. Other phases identified in the samples were melilite $\left(\mathrm{Ca}_{8} \mathrm{Al}_{6} \mathrm{MgSi}_{5} \mathrm{O}_{28}\right)$, manganese aluminate oxide $\left(\mathrm{Mn}_{2} \mathrm{AlO}_{4}\right)$ and glaucochroite $\left(\mathrm{CaMn}^{2+} \mathrm{SiO}_{4}\right)$.

\section{Discussion}

Synthesis of ferromanganese: Ferromanganese was not detected during the experiments. Partially reduced mixed manganese and iron oxides are detected, as we found jacobsite and iwakiite in the samples as main constituents $\left(\mathrm{Mn}^{2+}, \mathrm{Fe}^{2+}\right)\left(\mathrm{Fe}^{3+}, \mathrm{Mn}^{3+}\right)_{2} \mathrm{O}_{4}$ (substitutions and vacancies as expressed), while in the initial mixture we had $\mathrm{Mn}^{4+}$ and $\mathrm{Fe}^{3+}$. Regarding the $\mathrm{Mn}$ and Fe individual oxides, we found $\mathrm{MnO}$ and $\mathrm{Mn}_{3} \mathrm{O}_{4}\left(\mathrm{Mn}^{2+} \mathrm{Mn}^{3+}{ }_{2} \mathrm{O}_{4}\right)$, and $\mathrm{Fe}_{3} \mathrm{O}_{4}\left(\mathrm{FeOFe}_{2} \mathrm{O}_{3}\right)$ and $\gamma-\mathrm{Fe}_{2} \mathrm{O}_{3}$ Working under ambient atmosphere is unfavorable for the reduction reactions (even when using carbon excesses) because carbon was burned during the process and left the sample without fully reducing the load. Thermal decomposition allows the partial reduction of the mixture, but neither this method nor the carbon (nor the combined effects) allows obtaining the ferromanganese (Fe, Mn). Reactions solidsolid are difficult, and the expected solid-gas (carbon monoxide, Boudouard mechanism) reaction is minimized because hot gas tends to leave the sample without reducing because of the venetian blind (shutter) that allows the entrance of air from outside of the building causing circulation of air. The presence of a glass hood connected to a reducing or inert atmosphere would have been positive for the obtaining of ferromanganese. Temperature is also problematic, as if the temperature is increased to maximum values we did not improve the results, but we achieve the melting of the crucible and the appearance of silicates.

Ferromanganese and silicomanganese slags: Results are not satisfactory, complex silicates are the main phases identified together with manganese silicates and oxides (these in lower quantities). Calcium carbonate additions ( $6 \% \mathrm{wt}$.) did not play role in the treatment of the slags because it should have destroyed the silicates and liberate $\mathrm{Mn}$. The treatment is also limited by the depth that is possible to reach $(20 \mathrm{~mm}$ in depth). Increasing the additions could have improved the results, the same as the stirring during the process. If Mn would have been transformed into oxide (well-developed and with proper size), the sample could have been grinded and milled, and manganese oxides could have been recovered through gravimetric methods. These unfavorable results could make more interesting alternatively hydrometallurgical processes for manganese residues, as for instance, that used by Fernández-González et al., in the treatment of anodic lodes and scrapings from the zinc electrolytic process [10]. Maybe the addition of any reductant reagent or even increasing the quantity of calcium carbonate (or lime if calcined) would liberate manganese from the silicates present in the slag. Anyway, and as opposed to the iron by-products where iron can be removed from them through magnetic methods, manganese should be separated through gravimetric methods, and this requires a proper development and growth of the manganese phase to obtain it with the proper size for the gravimetric separation.

\section{Conclusions}

Concentrated solar thermal was used to obtain of ferromanganese. The lack of reducing atmosphere impeded the presence of reducing conditions that could have reduced iron and 
manganese oxides to obtain ferromanganese. This way, only partially reduced phases, as iwakiite and jacobsite, were detected.

Concentrated solar thermal was also used to treat silicomanganese and ferromanganese slags although with negative results. Manganese was not liberated from the slag as oxide (although oxides were identified) or any other phase. Additions of calcium carbonate were not enough to promote the destruction of manganese silicates and thus liberating this element. Further studies should be necessaries to evaluate the possibility of recovering manganese from these slags.

Author Contributions: D.F.-G. and L.F.V. conceived and designed the experiments; D.F.-G. performed the experiments; D.F.-G. and L.F.V. analyzed the data; D.F.-G. contributed reagents/materials/analysis tools;

D.F.-G. wrote the paper, and J.P.-N. reviewed the paper.

Acknowledgments: This research was supported by the Spanish Ministry of Education, Culture, and Sports via an FPU (Formación del Profesorado Universitario) grant to Daniel Fernández González (FPU014/02436). Financial support by the Access to Research Infrastructures activity in the 7th Framework Programme of the EU (SFERA 2 Grant Agreement n. 312643) is gratefully acknowledged and the use of the facilities and its researchers/technology experts (Project P1701250238, SOLMETBY, Investigation and evaluation of solar energy as energy source in the treatment of metallurgical by-products).

Conflicts of Interest: The authors declare no conflict of interest.

\section{References}

1. Fernández-González, D.; Ruiz-Bustinza, I.; González-Gasca, C.; Piñuela-Noval, J.; Mochón-Castaños, J.; Sancho-Gorostiaga, J.; Verdeja, L.F. Concentrated solar energy applications in materials science and metallurgy. Sol. Energy 2018, 170, 520-540, doi:10.1016/j.solener.2018.05.065.

2. Fernández-González, D.; Prazuch, J.; Ruiz-Bustinza, I.; González-Gasca, C.; Piñuela-Noval, J.; Verdeja, L.F. Solar synthesis of calcium aluminates. Sol. Energy 2018, 171, 658-666, doi:10.1016/j.solener.2018.07.012.

3. Fernández-González, D.; Prazuch, J.; Ruiz-Bustinza, I.; González-Gasca, C.; Piñuela-Noval, J.; Verdeja, L.F. Iron Metallurgy via Concentrated Solar Energy. Metals 2018, 8, 873, doi:10.3390/met8110873

4. Fernández-González, D.; Martín-Duarte, R.; Ruiz-Bustinza, I.; Mochón, J.; González-Gasca, C.; Verdeja, L.F. Optimization of sínter plant operating conditions using advanced multivariate statistics: Intelligent data processing. JOM-J. Miner. Met. Mater. Sci. 2016, 68, 2089-2095, doi:10.1007/s11837-016-2002-2.

5. Fernández-González, D.; Ruiz-Bustinza, I.; Mochón, J.; González-Gasca, C.; Verdeja, L.F. Iron ore sintering: Raw materials and granulation. Miner. Proc. Extr. Metal. Rev. 2017, 38, 36-46, doi:10.1080/08827508.2016.1244059

6. Fernández-González, D.; Ruiz-Bustinza, I.; Mochón, J.; González-Gasca, C.; Verdeja, L.F. Iron ore sintering: Process. Miner. Proc. Extr. Metal. Rev. 2017, 38, 215-227, doi:10.1080/08827508.2017.1288115.

7. Fernández-González, D.; Ruiz-Bustinza, I.; Mochón, J.; González-Gasca, C.; Verdeja, L.F. Iron ore sintering: Quality indices. Miner. Proc. Extr. Metal. Rev. 2017, 38, 254-264, doi:10.1080/08827508.2017.1323744.

8. Fernández-González, D.; Ruiz-Bustinza, I.; Mochón, J.; González-Gasca, C.; Verdeja, L.F. Iron ore sintering: Environment, automatic, and control techniques. Miner. Proc. Extr. Metal. Rev. 2017, 38, 238-249, doi:10.1080/08827508.2017.1288118.

9. Mochón, J.; Ruiz-Bustinza, I.; Vázquez, A.; Fernández, D.; Ayala, J.M.; Barbés, M.F.; Verdeja, L.F. Transformations in the iron-manganese-oxygen-carbon system resulted from treatment of solar energy with high concentration. Steel Res. Int. 2014, 85, 1469-1476, doi:10.1002/srin.201300377.

10. Fernández-González, D.; Sancho-Gorostiaga, J.; Piñuela-Noval, J.; Verdeja, L.F. Anodic lodes and scrapings as a source of electrolytic manganese. Metals 2018, 8, 162, doi:10.3390/met8030162.

(C) 2018 by the authors. Licensee MDPI, Basel, Switzerland. This article is an open access article distributed under the terms and conditions of the Creative Commons Attribution (CC BY) license (http://creativecommons.org/licenses/by/4.0/). 